\title{
Towards Adaptive E-Learning using Decision Support Systems
}

\author{
http://dx.doi.org/10.3991/ijet.v8iS1.2350
}

\author{
Maryam Yarandi, Hossein Jahankhani, Abdel-Rahman H. Tawil \\ University of East London, London, UK
}

\begin{abstract}
The significance of personalization towards learners' needs has recently been agreed by all web-based instructional researchers. This study presents a novel ontology semantic-based approach to design an e-learning Decision Support System (DSS) which includes major adaptive features. The ontologically modelled learner, learning domain and content are separately designed to support personalized adaptive learning. The proposed system utilise captured learners' models during the registration phase to determine learners' characteristics. The system also tracks learner's activities and tests during the learning process. Test results are analysed according to the Item Response Theory in order to calculate learner's abilities. The learner model is updated based on the results of test and learner's abilities for use in the adaptation process. Updated learner models are used to generate different learning paths for individual learners. In this study, the proposed system is implemented on the "Fraction topic" of the mathematics domain. Experimental test results indicated that the proposed system improved learning effectiveness and learner's satisfaction, particularly in its adaptive capabilities.
\end{abstract}

Index Terms-Adaptive learning, e-learning systems, Item response theory, Ontology, Personalised learning

\section{INTRODUCTION}

The success of web technologies has led to a growing attention on e-learning activities. However, most current e-learning systems provide static web-based learning so that learners access the same learning content through the internet, irrespective of individual learner's profile. These learners may have very different learning backgrounds, knowledge levels, learning styles, and abilities. The 'onesize-fit-all' in e-learning systems is clearly a typical problem. To overcome this limitation and increase effective learning, learning paths should be adapted to individual user's requirements [1]. Adaptive learning is a critical requirement for e-learning systems which dynamically adapts learning content to learner's educational needs for endorsing learning results [2]. However, such services are not often implemented properly in most cases of elearning as they require continuous fine tuning of the different features that should be used and when tuned how to use them.

Recent developments of semantic web technologies have shown a trend of using ontologies to promote adap- tive e-learning which allows creating specific user profiles and content models. Ontologies are the most suitable means for representing knowledge due to their flexibility and extensibility in designing concepts and their relationships [3].

In existing e-learning systems, same learning content is delivered to different learners. However, an enriched environment for one learner is not necessarily enriched for another. Preferences, ability and educational levels of learners are varied and various types of content on learning topics are required to adapt the learning content to the requirements of different learners. The complexity of existing e-learning systems is in selecting learning contents and sequences appropriate to particular learners. Currently, there are no systems that suggest to learners the appropriate learning content, activities and sequences based on learner's characteristics and analysis of previous learning steps. In this study, we present an innovative adaptive e-learning decision support system capable of suggesting learners' appropriate learning contents, activities and sequences by analysing user's profile model in an adaptive engine. Personalization and adaptation are achieved by designing appropriate semantic domains, learner model and content models separately to increase flexibility of the e-learning system. The user's profile data are collected via a registration process for learner's characteristics and is continuously updated from the results of tests throughout the process. The system also uses Item Response Theory (IRT) [4, 5] for calculating learner's abilities in order to be more accurate.

The Item Response Theory (IRT) is an item-oriented model based on the dependence between the characteristics of a test and the abilities of the examinee [6]. The item characteristics are referred to as the item difficulty, item discrimination, and the effect of random guessing. The main purpose of IRT is to estimate examinees abilities or proficiency according to his/her responses to test items [7].

The paper is organised as follows. The following section gives a background of current related works. After describing the architecture of the system in section 2 the ontologies that our approach is based on is explained in section 4. Section 5 presents our evaluation of system. Finally, we conclude the paper with directions for future research. 


\section{RELATED WORK}

Personalized services are nowadays an important research issue in the field of e-learning because no fixed learning paths will be appropriate for all learners (Chen 2008). It is commonly believed that every individual learns according to their own learning experience, style, needs and interest. Therefore, personalization and interactivity promotes the quality of learning for individual learners. Thus, in an e-learning system, the ability to identify and adapt learner's needs provide a powerful personalization mechanism.

To realise personalized learning, all users must have components in the user models. User models consists of a set of information which describes user characteristics such as preferences and background knowledge [8]. The system generates a better learning task by using the information in the user model. Furthermore, during the learning process user models will be constantly updated based on the interaction of the user with the learning environment.

Chen et al [9] developed a personalised adaptive elearning system using item response theory to which they enabled personalized learning according to difficulty parameters of course materials and learners' responses. Chen et al [10] also proposed a personalized mobile English vocabulary learning system based on Item Response Theory and learning memory cycles, which recommends appropriate English vocabulary for learning according to individual learner's vocabulary ability and memory cycle. Chen et al [11] also, present a personalized intelligent tutoring system to recommend courseware with suitable difficulty levels for learners and generate the content of courseware using fuzzy-based Item Response Theory. Baylari et al [7] developed a personalized multi agent e-learning system based on Item Response Theory (IRT) and Artificial Neural Networks (ANN) which presents adaptive tests (based on IRT) and personalized recommendations (based on ANN).

A personalized e-learning system must be able to tailor the educational experience to a particular learner. To achieve this goal, a semantic-based adaptive engine is proposed to analyze learners' responses and behaviour to regular activities and tests. During the next level of learning, the system suggests suitable learning paths based on analysed data in the adaptive engine.

A Decision Support System (DSS) is a computer-based system capable to support decision-making activities. DSS as part of e-learning systems can analyse data in users' profiles and allow the learners to select optimised learning paths. Zorrilla, García and Álvarez [12] proposed a decision support system which can help instructors to guide students using data mining techniques applied to data from LCMSs databases. Abu-Naser et al [13] proposed a decision support system to improve e-learning systems. The proposed DSS utilise the functionalities of database, Artificial Intelligence (AI), and data mining engines in an integrated way in order to extract the knowledge necessary to optimise the effectiveness of e-learning in educational institutions. Jeong, Choi, and Song [2] presents a Personalized Learning Course Planner (PLCP) with an E- learning Decision Support System (EL-DSS) that allows students to easily select the learning courses they desire. EL-DSS in PLCP analyses user profile data and, on the basis of the analyzed results, allows the student to select an optimised learning environment.

In this paper, we propose a DSS adaptive engine which suggests adaptive learning path according to analyzed result based on profile learner's modelled data.

\section{SYSTEM STRUCTURE}

In this section we comprehensively describe the architecture of our ontology-based adaptive e-learning DSS and demonstrate the individual components needed to implement our approach. The proposed architecture is depicted in Fig. 1.

The structure of the system consists of six components: User Interface, Courseware manager, Content Mediator, User Mediator, Test Mediator and Adaptive Engine. The user interface deals with the learner's registration, login process and the learner studies with a recommended learning topic by the adaptive engine. It also takes learner's responses from the test items and transfers them into the Adaptive Engine. The courseware manager allows the instructors to update the content and test repositories through their respective mediators. The different mediators are responsible for handling requests for interacting with the repository to retrieve and update the information. The Adaptive Engine (AE), at the heart of our architecture is responsible for suggesting adaptive learning paths according to learner's characteristics and the result of exercises and tests in previous steps of the learning process.

The structure of the adaptive engine is shown in Fig. 2. Considering that our architecture is comprehensive, the proposed engine does not contain the strategies and knowledge for a particular learning domain, this is entirely ontology driven. However, it consists of five components, Activity Unit, Test Unit, Learning Result Analyser, Course Structure Constructor and Decision Support System.

The learning result analyser analyses the activities and test results from the activity and test units and transfers the result to the DSS. The Course Structure Constructor performs the process of constructing the annotated course structure by using link annotations and link hiding to offer adaptive navigational support techniques (Brusilovsky, 2007) which helps the learner in navigate the domain space. Links to topics with different educational status are marked differently. This Constructor gets learner's level of knowledge from learner's model and the structure of the course from domain model to construct proposed annotated course structures. The main part of the AE is the DSS. The AE obtains knowledge about learners, content information and course structures through related mediators. Subsequently, it classifies this information, analysed previous learning activities, analysed test result to generate the best learning paths (that is, learning content, activities and sequences) personalized for specific learners. The recommended learning path is presented to the learner via the User Interface. 


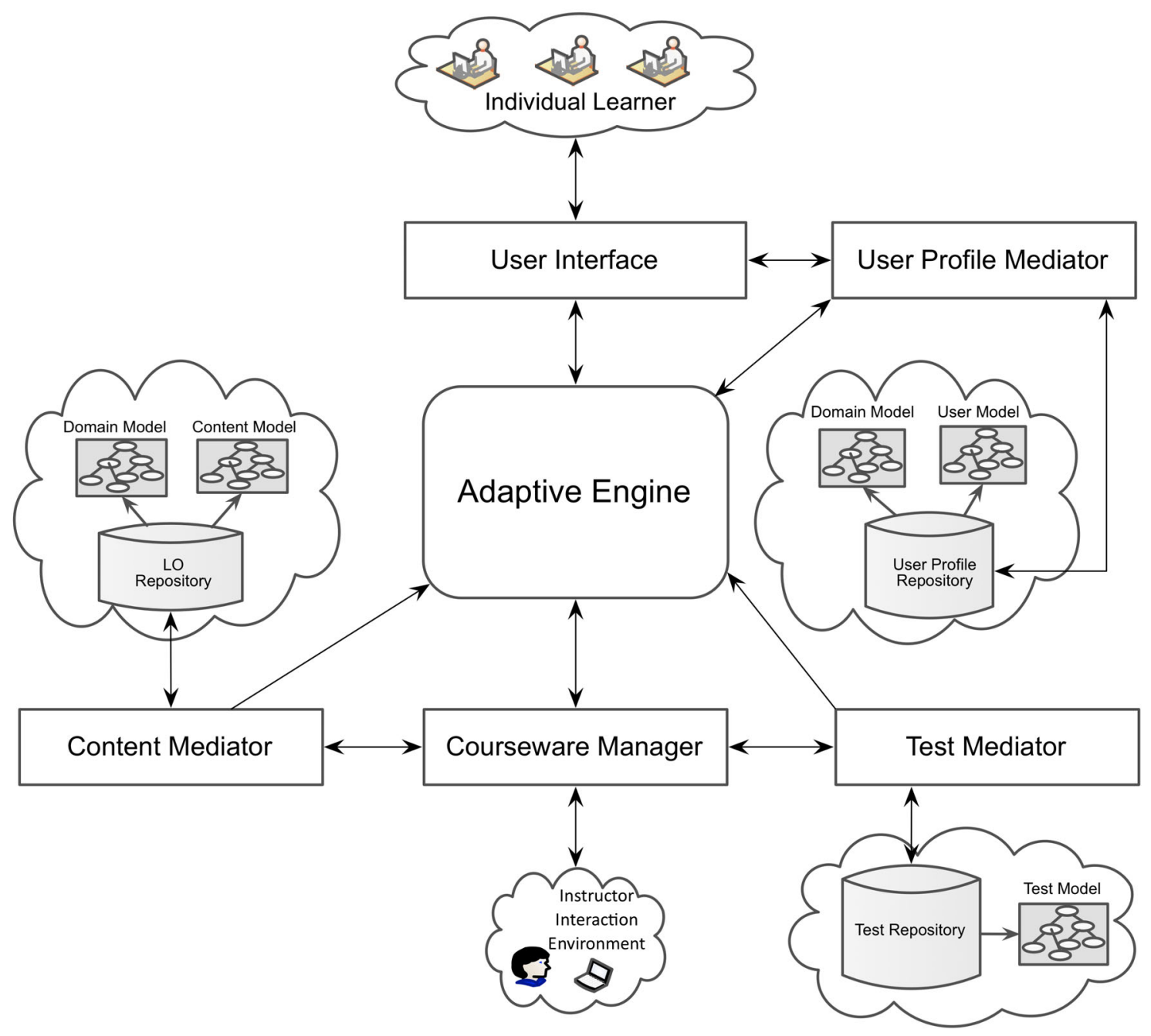

Figure 1. The Architecture of Adaptive E-learning with Decision Support System

\section{A. Adaptive Decision support system}

The main purpose of DSSs in our approach is to suggest optimized learning paths based on previous learning information about learners. The Decision Support System supports adaptivity from two aspects: Firstly, it provides different presentation and levels of learning contents for learner's with different characteristics (e.g. learning styles, ability, preferences) (Maryam Yarandi, Tawil, \& Jahankhani, 2012); Secondly, it suggests adaptive learning paths (such as, learning a new topic, repeat this topic with more details, read more examples, doing more exercises with lower or higher difficulty levels, repeat of prerequisite topics) according to analysed previous learning activities and analysed test results. The structure of our adaptive DSS is represented in Fig. 3. According to Item Response Theory (IRT) learner's response to test is analysed by the IRT Analyser to obtain learners' new abilities (M. Yarandi, Jahankhani, \& Tawil, 2012). The Data Organiser adjusts all data about content, course structure, analysed exercises and test and also information about previous recommendation based on attributes of learner profile. Using this adapted knowledge, the DSS calculates the appropriate learning path recommendation and best learning content for the learner. The calculated results are provided for the learner by the Content and Learning Path Decision Makers

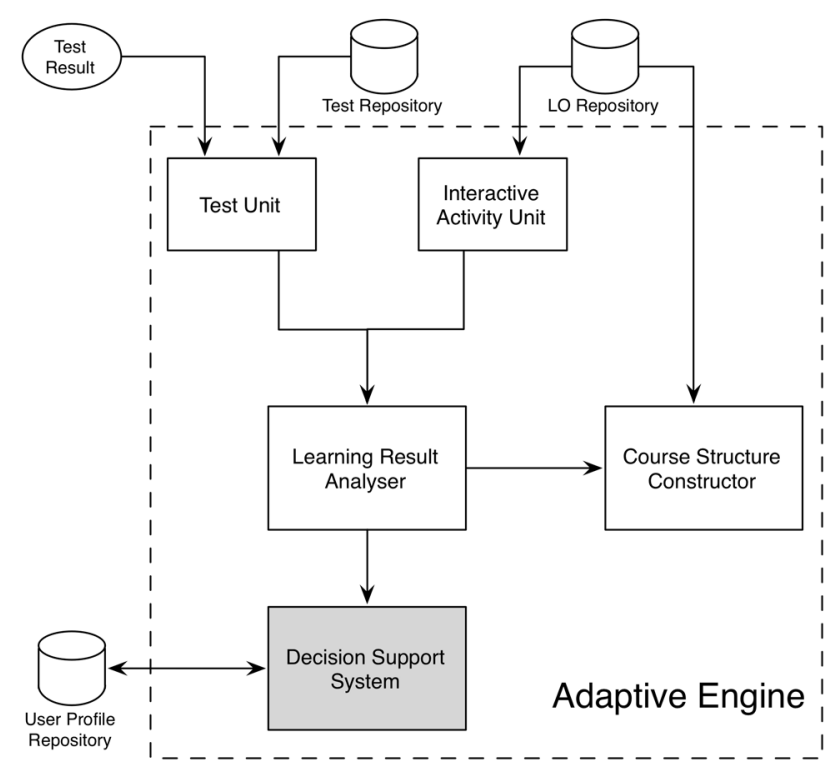

Figure 2. The Structure of Adaptive Engine. 


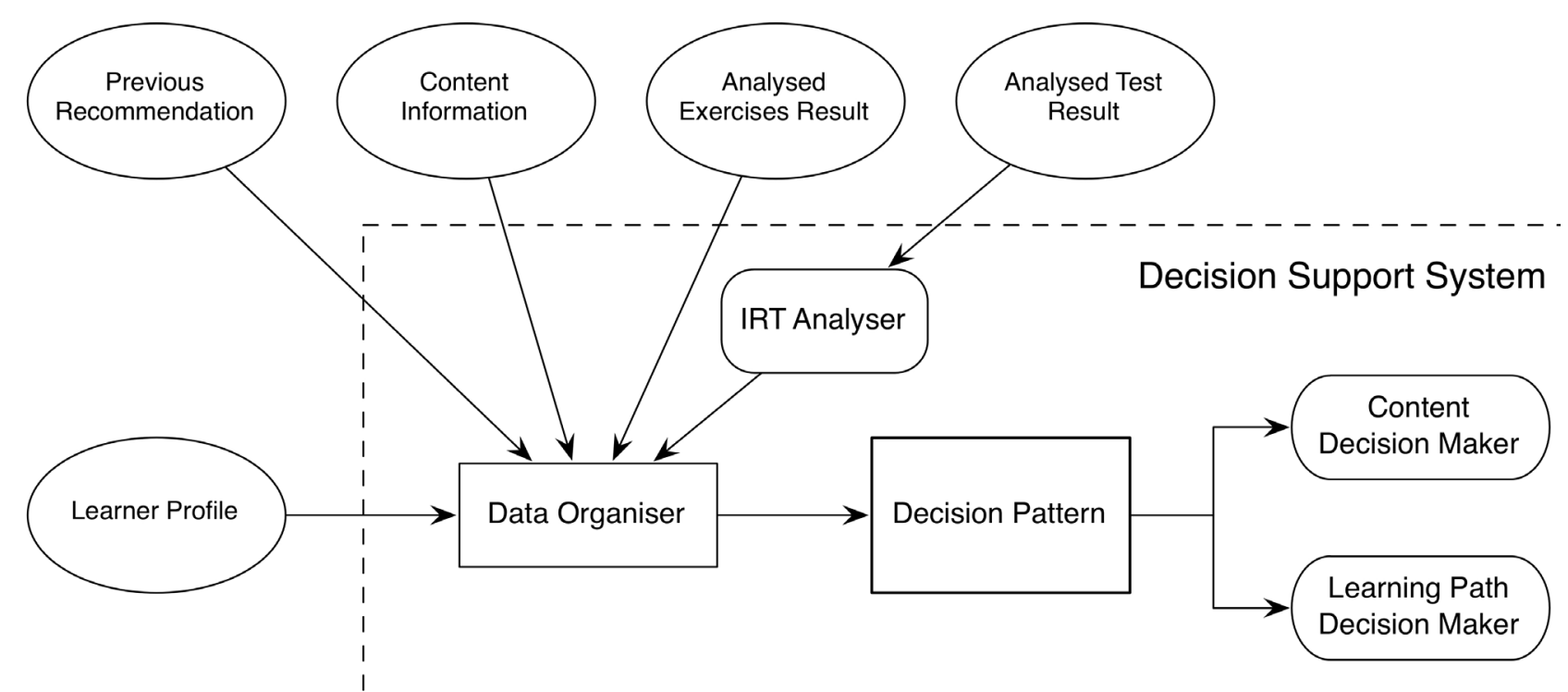

Figure 3. The Structure of DSS

\section{B. IRT Analyser}

To estimate learner's abilities, the item response theory propose different characteristic functions [4, 5]. In this paper, the item characteristic function with three parameters is used to model items in the tests. The equation for this model is given by the following formula:

$$
P_{i}(\theta)=c_{i}+\left(1+c_{i}\right) \frac{1}{1+\exp \left(-a_{i}\left(\theta-b_{i}\right)\right)}
$$

Where:

$\theta$ is the ability level of learner

$\mathrm{a}_{\mathrm{i}}$ is the discrimination degree of item $\mathrm{i}$ a constant 1.702

$b_{i}$ is the difficulty parameter of item $i$

$c_{i}$ is the guess degree of item $i$

$\mathrm{P}\left(\theta_{\mathrm{i}}\right)$ is the probability that a learner with ability $\theta$ can response correctly to the item $i$.

Under IRT, Maximum Likelihood Estimator (MLE) is applied to effectively estimate the learner's abilities [6]. Bock and Mislevy derived the quadrature form to estimate learner ability [14]. In order to estimate the ability of a learner, an unknown value, this estimator assumes that all the numerical items parameters in the test are known. The direct result is that the scale of the measurement is the same as the scale of the parameters in the items. After completing the item and receiving the response of the learner to all items of a test, the items are dichotomously scored. This means that the learner gets one for the correct answer and zero for the incorrect answer. Hence, we will have a response pattern $\left(\mathrm{U}_{1}, \mathrm{U}_{2}, \mathrm{U}_{3}, \ldots, \mathrm{U}_{\mathrm{j}}, \ldots ., \mathrm{U}_{\mathrm{n}}\right)$ which is called test response vector, where $U_{j}=1$ represents a correct answer given by the learner for the $j^{\text {th }}$ item in the test. On the contrary, $\mathrm{U}_{\mathrm{j}}=0$ represents an incorrect answer given by the learner for the $\mathrm{j}^{\text {th }}$ item in the item.

The estimation formula is as follows:

$$
\hat{\theta}=\frac{\sum_{\mathrm{k}}^{\mathrm{q}} \theta_{\mathrm{k}} L\left(u_{1}, u_{2}, \ldots, u_{n} \mid \theta\right) \mathrm{A}\left(\theta_{\mathrm{k}}\right)}{\sum_{\mathrm{k}}^{\mathrm{q}} L\left(u_{1}, u_{2}, \ldots, u_{n} \mid \theta\right) \mathrm{A}\left(\theta_{\mathrm{k}}\right)}
$$

Where $\theta$ is the estimation of the ability of the learner is $L\left(u_{1}, u_{2}, \ldots, u_{n} \mid \theta\right)$, the value of likelihood function and $A(\theta)$ represents the quadrature weight at a level below the learner's ability. The likelihood function is calculated as follows:

$$
L\left(\theta \mid u_{1}, u_{2}, \ldots, u_{n}\right)=\prod_{i=1}^{n} P(\theta)^{u_{i}} Q(\theta)^{\left(1-u_{i}\right)}
$$

Where $\operatorname{Pi}(\theta)$ denotes the probability that the learner responds correctly to the $i^{\text {th }}$ item at a level below the ability level $\theta, \mathrm{Q}_{\mathrm{i}}(\theta)=1-\mathrm{P}_{\mathrm{i}}(\theta)$ represents the probability that the learner responds incorrectly to the $i^{\text {th }}$ item at a level below the ability level $\theta, \mathrm{u}_{\mathrm{i}}=1$ if the answer of $\mathrm{i}^{\text {th }}$ is correct and $\mathrm{u}_{\mathrm{i}}=0$ if the answer of $\mathrm{i}^{\text {th }}$ is incorrect [10]. The learner ability is updated based on test results learned from the item response theory.

\section{Decision Pattern}

In this section, the Decision Pattern is explained to organise the adaptive learning path according to the learner's characteristics and analysed exercises score. Decision Pattern is fully domain and instructional design independent based on using appropriate domain ontologies. In other words, it does not contain the strategies and knowledge for a particular domain nor instructional design. As listed in Table 1, the adaptive learning path is recommended to learner according to level of exercises, analysed exercises result, difficulty level of content and defined activities in instructional design. In the first session, learning contents with a moderate difficulty level are assigned to learners as the system has no previous learning information. However, after the learners carries out his/her studies, the IRT Analyser estimates learner abilities and adjusts the difficulty level of the learning contents based on learner's response to the tests. For instance, as indicated in the second row of the table, if a learner is given a learning content with moderate or high difficulty level and he/she fails to answer the related easy exercises, the decision Pattern recommends him/her to repeat learning this topic with more details (with lower difficulty). 
SPECIAL FOCUS PAPER

TOWARDS ADAPTIVE E-LEARNING USING DECISION SUPPORT SYSTEMS

TABLE I.

THE RECOMMENDATION PATTERN

\begin{tabular}{|c|c|c|c|c|}
\hline $\begin{array}{l}\text { Level of } \\
\text { Exercises }\end{array}$ & $\begin{array}{l}\text { Result of Exer- } \\
\text { cises }\end{array}$ & $\begin{array}{l}\text { Difficulty level of content } \\
\text { based on ability level of } \\
\text { learner }\end{array}$ & $\begin{array}{l}\text { Last Activity of } \\
\text { Instructional Design }\end{array}$ & Learning path Recommendation \\
\hline Easy & Pass & - & - & Please do more exercises with higher difficulty level \\
\hline Easy & Fail & Moderate/High & - & Please repeat learning of this topic with more detail \\
\hline Easy & Fail & Low & - & Please repeat Prerequisite of this topic \\
\hline Moderate & Pass & - & - & $\begin{array}{c}\text { Please do more exercises with higher difficulty or do } \\
\text { related test }\end{array}$ \\
\hline Moderate & Fail first time & - & - & $\begin{array}{l}\text { Please read More examples and do more exercises } \\
\text { for better understanding }\end{array}$ \\
\hline Moderate & Fail second time & Moderate/High & - & Please repeat learning of this topic with more detail \\
\hline Moderate & $\begin{array}{c}\text { Fail } \\
\text { second time }\end{array}$ & Low & - & Please repeat Prerequisite of this topic \\
\hline Difficult & Pass & - & No & $\begin{array}{c}\text { Please continue to do more activities or do related } \\
\text { test }\end{array}$ \\
\hline Difficult & Pass & - & Yes & You finish this topic. Please do related test \\
\hline Difficult & Fail & - & - & $\begin{array}{c}\text { Please read more examples and do more exercises } \\
\text { for passing this level or do related test for finishing } \\
\text { learning this topic }\end{array}$ \\
\hline
\end{tabular}

\section{SEMANTIC MODEL}

Using ontologies in our proposed system has the benefit of building reusable modular systems capable to reflect individual learner's needs. Additionally, in order to facilitate direct access to course components a semantic representation of course structures is defined in our system [15]. Consequently, the same learning content can be presented in different ways to tailor learning content according to preferences, abilities, learning style, and other specific features of a learner that is relevant for the learning process. Therefore, we are able to create on the fly adaptive learning path out of those components.

Four ontology-based knowledge models namely Domain, Test, Learner and Content model are designed to recommend adaptive learning paths. The domain model consists of some classes and properties to define the topics of a domain and semantic relationships between them. The Test model is developed to formally represent relevant information about different tests, especially the parameters which are used to calculate learners' abilities based on the IRT. The learner model ontology is designed to present personal information and learning characteristics of learners which has previously interacted with the system. This ontology is required by the system to perform personalized reasoning based on the captured user profile. Fig. 4 shows the content ontology to which Instructional objects are applied. It describes the structure of courses and their components.

This model is designed to define instructional objects that form the structure of the courses. The proposed ontology includes three levels of hierarchy namely Course, Lesson and Instructional objects to present LOs structure; these are explained as follows:

- The Course class: is the first level of the hierarchy which consist of several Lessons classes determined via the hasPart property. In order to describe a course some metadata such as name, description, contributor and keyword are attached to this class through some data properties.

- The Lesson class: this class is an aggregation of both the InstructionalObject class and Test class through the hasPart property. The Test class represent documents for evaluating learners prior to the start of the next lesson. Lesson class also includes some metadata like name, description, contributor and keyword to describe a lesson. The navigational relationship between Lesson classes is defined through next and previous properties.

- Instructional objects: instructional objects (IOs) are considered from the perspective of their instructional roles. Therefore, classes such as Example, Definition, Exercise, References are defined as subclasses of the InstructionalObject class. This class is attached to metadata that describes IOs via data properties such as hasName, keyword, difficultyLevel and description.

The proposed ontology is designed to describe independent, modular instructional objects, which are served as a building block for creating tailored learning content. A number of these instructional objects are assembled in different ways to generate adaptive learning paths based on learners' preferences.

\section{Fraction LEARNING SySTEM WITH DSS}

In this study, the adaptive decision support system is implemented on "Fraction topic" of the mathematics domain to verify the effectiveness of the system. The proposed DSS is domain independent and it can be easily repurposed for other domains if suitable domain ontology is designed. 


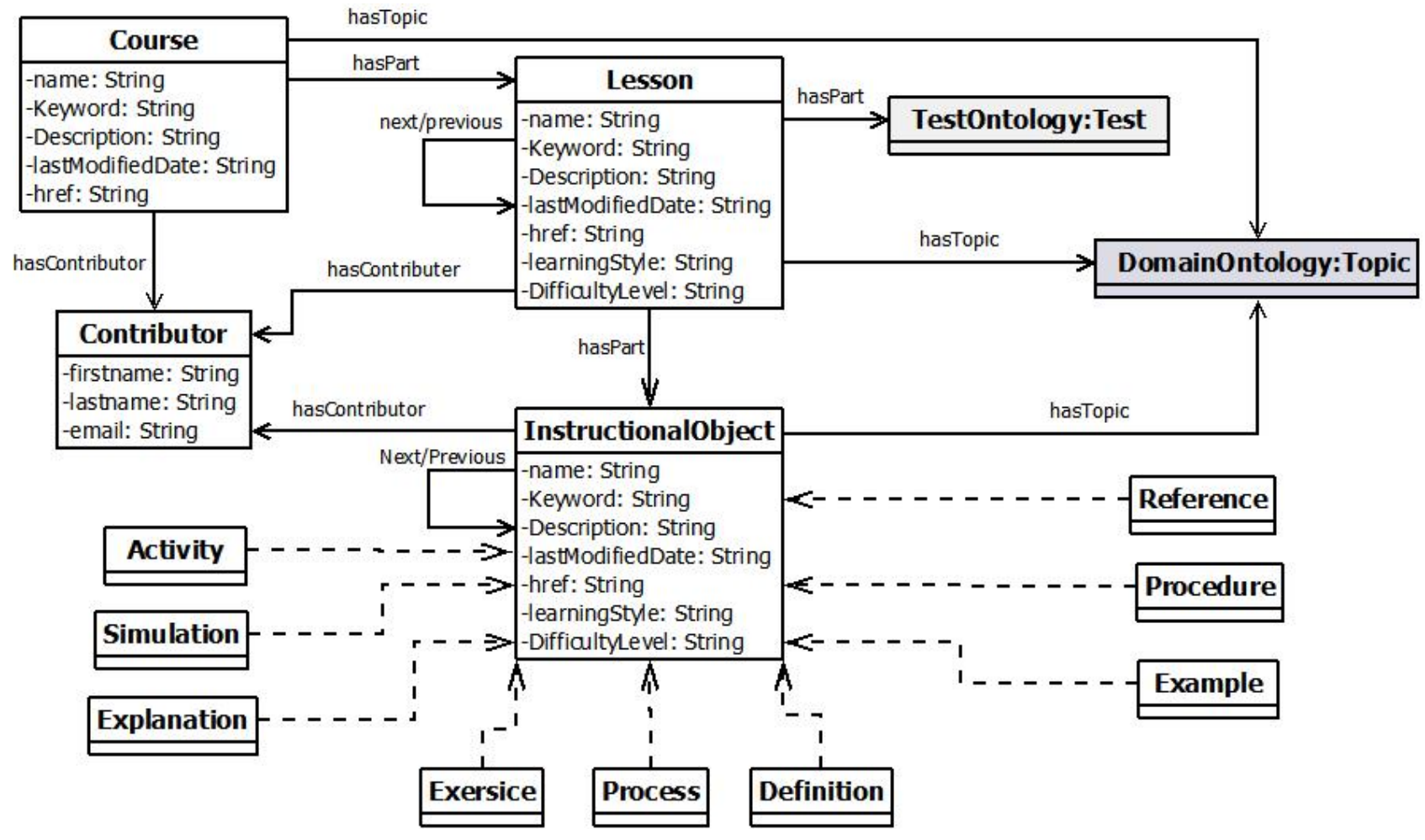

Figure 4. The Content Ontology

At the start of the first session learners should complete a registration process. During this process general and educational characteristics of individual learners are recorded and a first version of the learner model is created. For this purpose, the system presents newly subscribed learners with a questionnaire to realize the learner's learning styles. The learner is also asked to estimate his levels of knowledge regarding the topics of the domain being taught.

A learning session starts after a registered learner logging into the system. According to information in the learner's model the structure of course is presented to the learner in the form of annotated course structure by using link annotations and link hiding of adaptive navigation support techniques (Brusilovsky, 2007). Links to topics with different educational status are marked differently. In our system utilised link annotations are as follows:

- Purple colour denotes that the learner knows the topic that the links points to.

- Blue colour represents recommended topics, a topic that the learner is capable to learn and has knowledge about all prerequisites.

- Grey colour denotes a topic that the learner is still not ready to learn as he does not have enough knowledge about related prerequisite topics and there is no indication from his profile that he completed that topic.

Link hiding techniques are used to reduce learners' cognitive load. In our system links annotated with grey colours are made inactive and the learner does not have access to the details of topics which are considered too advanced for him. Accordingly, the learner is free to choose one of the topics with either purple or blue colours. Fig. 5 shows a screenshot of the course structure according to the information in learner model.
As topic selection is being made, the system uses adaptive presentation technique (Conlan, 2006) to adapt learning content to specific learner's needs. Therefore, it assembles dynamically personalized learning based on information gathered from the learner's model, learning design which is made by content authors and instructional objects available in its learning objects repository. After this process is finished the learner is presented with individually tailored content specific to his preferences and profile. Fig. 6 shows the content that the learner will learn.

Fig. 7 shows the screen for the exercises that the learner has to take during the study session. The number of questions for the test after the study is comprised of questions from the Questions Bank in Fig. 1 in the even ratio per unit. The exercise results and explanation about correct answer are displayed to the learner.

As explained before, during the next study session, the DSS suggests the optimised learning path to the learner according to the current learning session and analysed learning exercises, as is displayed in Fig. 8.

After finishing learning the entire topic, the system selects and presents a suitable test to the learners. According to IRT, the collected learner's responses are analysed in order to estimate the ability of the learner (Yarandi, Jahankhani, et al., 2011). Subsequently, the learner model is updated based on the information obtained from result of examinations. Therefore, when the learner is back to the annotated course structure, he/she can select the next level of the learning process where recommended topics and contents will be adapted based on new information available from the updated learner's model. 


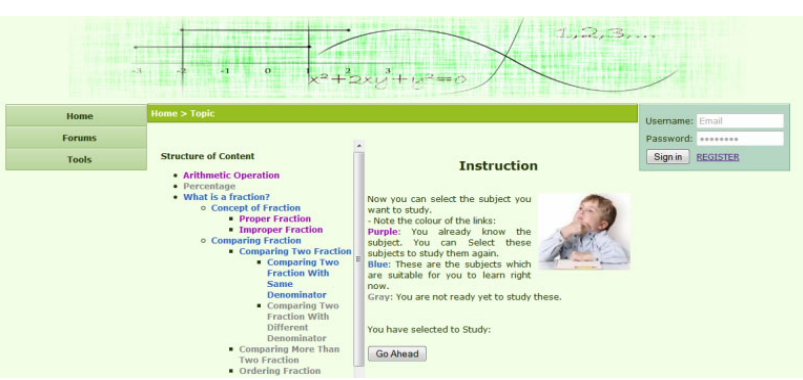

Figure 5. a screenshot of course structure based on learner model

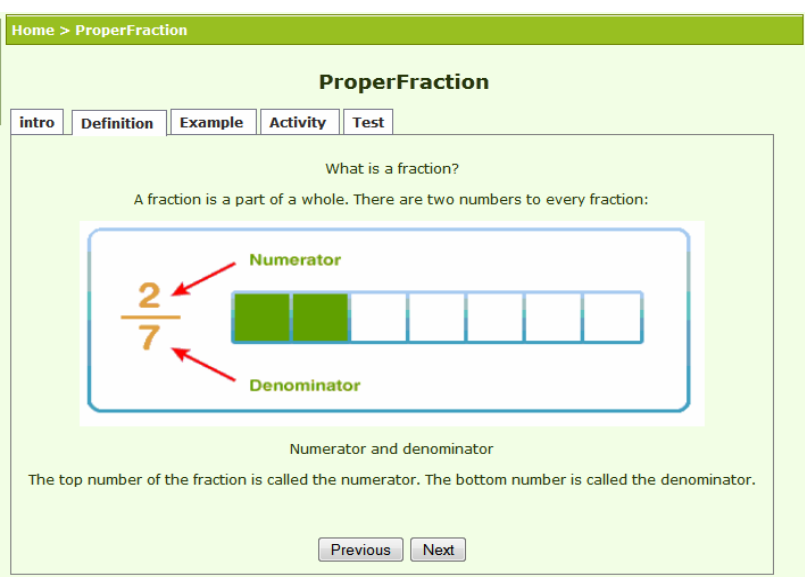

Figure 6. Learning contents screen

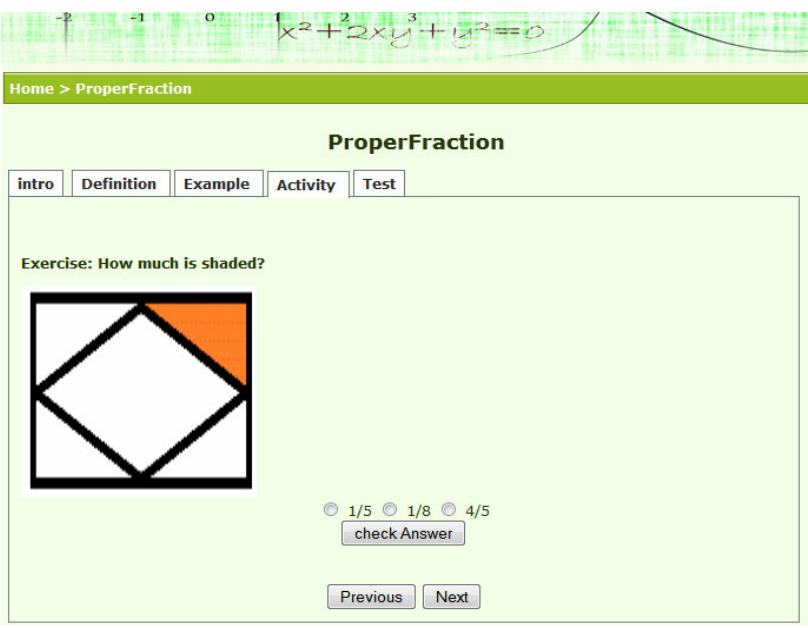

Figure 7. Exercise screen

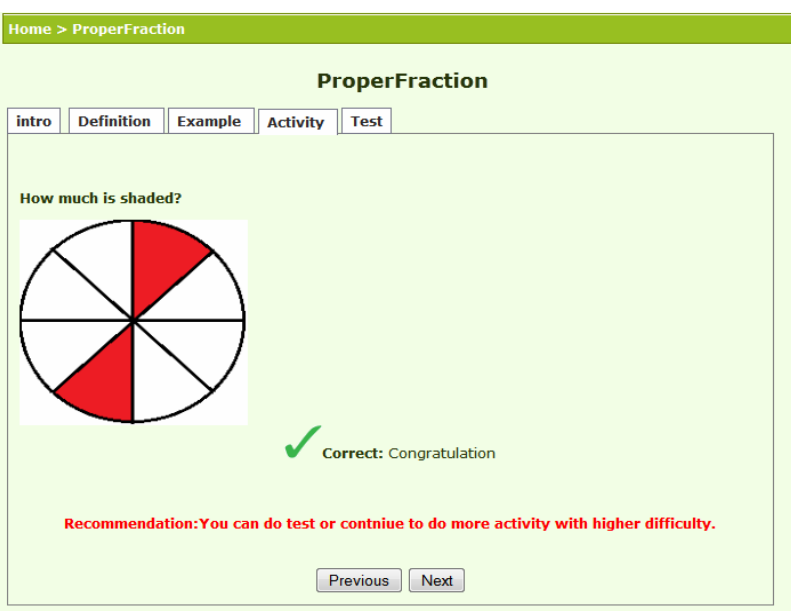

Figure 8. Recommendation of the learning path during the next study session

\section{EVALUATION}

To evaluate the effectiveness of the proposed system, we conducted an experiment with a Fraction learning system for the mathematics domain described in previous section. The system was used as part of an elementary school lesson to teach the topic of fractions in mathematics course. To evaluate learner's satisfaction with the adaptive learning system, a questionnaire was designed to measure whether or not the proposed learning system with adaptive features satisfies the real requirements of most learners.

We selected 40 applicants with varied learning abilities who were interested to test the adaptive learning system. The learners were randomly assigned into two groups. One group has studied with the adaptive system while the other group used the non-adaptive system. Each group contains 40 learners with the average age being around 9 years old.

To evaluate learners' satisfaction with the proposed adaptive system, inspired from [16] evaluation technique, a questionnaire involving 12 questions, with distinguished four various types was designed to measure whether the provided services in the proposed learning system satisfy the real requirements of learners. Four question types have been assigned to check learners' interests, level of effectiveness of interaction with the system and to find out whether the system has improved their satisfaction.

In the questionnaire, learners were asked to express their satisfaction with the statements, based on the five Likert-type scale [17] ranging from 'strongly agree' to 'strongly disagree'. The results are presented in Table II.

Results of the questionnaire analysis indicate that the proposed adaptive system improved learners' satisfaction, particularly in its adaptive capabilities. Qualitative feedback from the interviews has shown that suggesting an adaptive learning path is suitable to learners' historical learning activities, improves learner's interest and satisfaction in e-learning systems.

\section{CONCLUSION}

To enhance instructional efficiency, e-learning systems should understand learning requirements of learners so as to prepare and design appropriate learning paths and content purposely for individual learners. This study presents a novel ontology-based approach to design an elearning Decision support system which recommends adaptive learning paths personalized to particular learners. The user profile data are collected via a registration process for learners' characteristics and the result of activities tests during the learning process. The adaptive engine suggested in this paper analyses user profile data, based on the analysed results, recommends an appropriate learning path to the learner. According to IRT, learner's responses to test items are analysed to calculate learner's abilities. The system recognizes changes in the learner's levels of knowledge as they progress and the learner model are progressively updated based on learners' progress and abilities. Four models which have been realised by the ontology based knowledge modelling approach are included as part of our system: domain model, user model, content model and test model. The evaluation results indicate that the proposed learning method can effectively improve learners’ satisfaction in e-learning systems. 
TABLE II.

THE SATISFACTION EVALUATION RESULTS OF QUESTIONNAIRE

\begin{tabular}{|c|c|c|c|c|c|c|}
\hline \multirow{2}{*}{$\begin{array}{l}\text { Question } \\
\text { Type }\end{array}$} & \multirow{2}{*}{ Items } & \multicolumn{5}{|c|}{ Satisfaction Degree } \\
\hline & & $\begin{array}{l}\text { Strongly } \\
\text { agree }\end{array}$ & Agree & No opinion & Disagree & $\begin{array}{l}\text { Strongly } \\
\text { Disagree }\end{array}$ \\
\hline \multirow{3}{*}{$\begin{array}{l}\text { Learning } \\
\text { interests }\end{array}$} & 1- I agree that using this system can promote my learning interests. & 8 & 19 & 1 & 2 & 0 \\
\hline & 2- I agree that this learning system is user-friendly. & 6 & 19 & 3 & 2 & 0 \\
\hline & $\begin{array}{c}\text { 3- I feel that the time passes very quickly when I use this system to learn } \\
\text { mathematics. }\end{array}$ & 5 & 14 & 9 & 2 & 0 \\
\hline \multirow{2}{*}{$\begin{array}{l}\text { Learning } \\
\text { interaction }\end{array}$} & $\begin{array}{c}\text { 1- I agree that this learning system provides interactive features between } \\
\text { learners and the system. }\end{array}$ & 10 & 15 & 1 & 4 & 0 \\
\hline & $\begin{array}{l}\text { 2- I agree that this learning system provides a personalized information } \\
\text { presentation. }\end{array}$ & 4 & 18 & 5 & 3 & 0 \\
\hline \multirow{3}{*}{$\begin{array}{l}\text { Learning } \\
\text { performance }\end{array}$} & $\begin{array}{l}\text { 1- I agree that using the system can effectively help me to understand } \\
\text { mathematical concepts. }\end{array}$ & 11 & 15 & 3 & 1 & 0 \\
\hline & 2- I feel that this system promotes my learning confidence. & 5 & 12 & 8 & 4 & 1 \\
\hline & $\begin{array}{l}\text { 3- I agree that my mathematical score has progressed due to using this } \\
\text { system. }\end{array}$ & 12 & 17 & 1 & 0 & 0 \\
\hline \multirow{4}{*}{$\begin{array}{l}\text { Learner's } \\
\text { satisfaction }\end{array}$} & $\begin{array}{l}\text { 1- I agree that the personalised services provided by the system satisfy } \\
\text { my requirements. }\end{array}$ & 10 & 18 & 1 & 1 & 0 \\
\hline & 2- I am satisfied with the quality of the system. & 5 & 21 & 2 & 2 & 0 \\
\hline & $\begin{array}{l}\text { 3- I am satisfied with the difficulty level of learning content, activities } \\
\text { and tests. }\end{array}$ & 7 & 20 & 2 & 1 & 0 \\
\hline & 4- I am satisfied with the recommended adaptive learning path. & 9 & 19 & 1 & 1 & 0 \\
\hline
\end{tabular}

\section{REFERENCES}

[1] V. Esichaikul, S. Lamnoi, and C. Bechter, "Student Modelling in Adaptive E-Learning Systems," Knowledge Management \& ELearning: An International Journal, vol. 3, pp. 342-355, 2011.

[2] H.-Y. Jeong, C.-R. Choi, and Y.-J. Song, "Personalized Learning Course Planner with E-learning DSS using user profile," Expert Systems with Applications, vol. 39, pp. 2567-2577, 2012. http://dx.doi.org/10.1016/j.eswa.2011.08.109

[3] P. Mohan and C. Brooks, "Learning objects on the semantic Web," in Advanced Learning Technologies, 2003. Proceedings. The 3rd IEEE International Conference on, 2003, pp. 195-199.

[4] F. B. Baker, The basics of item response theory, second ed. Washington: ERIC clearing house on assessment and evaluation, 2001.

[5] F.-H. Wang, "Application of componential IRT model for diagnostic test in a standard conformant elearning system," presented at the Sixth IEEE International Conference on Advanced Learning Technologies, 2006. http://dx.doi.org/ 10.1109/ICALT.2006.1652414

[6] R. K. Hambleton, H. Swaminathan, and H. J. Rogers, Fundamentals of Item Response Theory. London: Sage publications, the International Professional Publishers, 1991.

[7] A. Baylari and G. A. Montazer, "Design a personalized e-learning system based on item response theory and artificial neural network approach," Expert Systems with Applications, vol. 36, pp. 80138021, 2009. http://dx.doi.org/10.1016/j.eswa.2008.10.080

[8] E. Alfonseca, P. Rodríguez, and D. Pérez, "An approach for automatic generation of adaptive hypermedia in education with multilingual knowledge discovery techniques," Computers \& Education, vol. 49, pp. 495-513, 2007. http://dx.doi.org/10.1016/ j.compedu.2005.10.007

[9] C.-M. Chen, H.-M. Lee, and Y.-H. Chen, "Personalised e-learning system using item response theory," Computers \& Education, vol. 44, pp. 237 - 255, 2005. http://dx.doi.org/10.1016/j.compedu. 2004.01.006

[10] C.-M. Chen and C.-J. Chung, "Personalized mobile English vocabulary learning system based on item response theory and learning memory cycle," Computers \& Education vol. 51, pp. 624647, 2008. http://dx.doi.org/10.1016/j.compedu.2007.06.011
[11] C.-M. Chen and L.-J. Duh, "Personalized web-based tutoring system based on fuzzy item response theory," Expert Systems with Applications, vol. 34, pp. 2298-2315, 2008. http://dx.doi.org/10.1016/j.eswa.2007.03.010

[12] M. Zorrilla, D. García, and E. Álvarez, "A decision support system to improve e-learning environments," presented at the Proceedings of the 2010 EDBT/ICDT Workshops, Lausanne, Switzerland, 2010.

[13] S. Abu-Naser, A. Al-Masri, Y. A. Sultan, and I. Zaqout, "A Prototype Decision Support System For Optimizing The Effectiveness Of Elearning In Educational Institutions," International Journal of Data Mining \& Knowledge Management Process (IJDKP), vol. 1, pp. 1-13, 2011. http://dx.doi.org/10.5121/ijdkp.2011.1401

[14] F. B. Baker, Item Response theory: Parameter estimation techniques. New York: Marcel Dekker, 1992.

[15] M. Yarandi, A. R. Tawil, and H. Jahankhani, "Adaptive ELearning System Using Ontology," presented at the 22nd International Workshop on Database and Expert Systems Applications, Toulouse, France, 2011.

[16] C.-M. Chen, Y.-L. Hsieh, and S.-H. Hsu, "Mining learner profile utilizing association rule for web-based learning diagnosis," Expert Systems with Applications, vol. 33, pp. 6-22, 2007. http://dx.doi.org/10.1016/j.eswa.2006.04.025

[17] R. Likert, A technique for the measurement of attitudes. New York: Archives of Psychology, 1932.

\section{AUTHORS}

Maryam Yarandi, Hossein Jahankhani, and AbdelRahman H. Tawil are with School of Architecture, Computing and Engineering, University of East London, London, United Kingdom, (0934309@uel.ac.uk, H.Jahankhani@uel.ac.uk, A.R.Tawil@uel.ac.uk).

This article is an extended and modified version of a paper presented at the International Conference on Interactive Collaborative Learning (ICL2012), held 26 - 28 September 2012, in Villach, Austria. 